\title{
Depth-of-Field of the Accommodating Eye
}

\author{
Paula Bernal-Molina*, Robert Montés-Micó ${ }^{\dagger}$, Richard Legras ${ }^{\dagger}$, and Norberto López-Gil ${ }^{\dagger}$
}

\begin{abstract}
Purpose. To obtain experimental values of the depth-of-field (DOFi) of the human eye for different accommodative states. Methods. First, the monochromatic ocular wavefront of seven eyes from young subjects (mean $[ \pm$ SD] age, 29.7 [ \pm 7.7$]$ years) was measured at eight different accommodative demands (ADs) (from -1 to 6 diopters [D] in steps of $1 \mathrm{D}$ ). Then, in a second part, accommodation was paralyzed and an adaptive optics system was used to correct the aberrations of the paralyzed eye and to simulate, with the aid of an artificial pupil, the wavefront of the accommodated eye. The simulation was performed for each AD measured in the first part of the experiment. A Badal system was used to modify the stimulus vergence so as to obtain three repeated measurements of the subjective DOFi, based on the criterion of an objectionable blur.

Results. When increasing AD from 0 to $6 \mathrm{D}$, the mean intersubject pupil diameter and DOFi changed from 5.70 to $4.62 \mathrm{~mm}$ and from $0.85 \pm 0.26 \mathrm{D}$ to $1.07 \pm 0.19 \mathrm{D}$, respectively. All subjects presented a similar DOFi for all AD (intrasubject SD never exceeded $0.23 \mathrm{D})$. Paraxial accommodation response showed a lag that increased with the AD. For the lowest $(0 \mathrm{D})$ and the highest $(6 \mathrm{D})$ values of $\mathrm{AD}$, the refractive state of the eye was close to the nearest and furthermost ends of the DOFi, respectively.

Conclusions. The visual system takes advantage of the DOFi to change the refractive state less than necessary to form the paraxial image at the retina when it comes to focusing a near target ( 5 to $6 \mathrm{D}$ of $\mathrm{AD}$ ). This indicates that the main purpose of accommodation is not to maximize retinal image quality but to form one that is good enough.
\end{abstract}

(Optom Vis Sci 2014;91:1208-1214)

Key Words: depth-of-focus, depth-of-field, accommodation, aberrations, spherical aberration, adaptive optics, accommodative lag, pupil, accommodation response

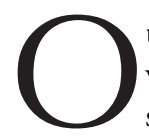
ur eyes project information from a three-dimensional world to a basically two-dimensional surface, corresponding to the photoreceptor plane in the retina. In theory, only one plane or surface of world can be in focus at one time. However, the eye exhibits a certain tolerance to out-of-focus images, a feature that is known as depth-of-focus (DOF). The corresponding distance range in which the objects are seen "clearly" is known as depth-of-field (DOFi). Although DOF and DOFi refer to an interval of distances or a dioptric range in the image and object space, respectively, both parameters define a similar concept and are usually interchangeable. This article will mainly refer to DOFi because it represents a more practical parameter, which can usually be determined through direct measurement.

It is a well-known fact that certain optical and neural factors can change the DOFi. One of the most important ones is pupil size ${ }^{1}$;

\footnotetext{
${ }^{*} \mathrm{MSc}$

${ }^{\dagger} \mathrm{PhD}$

Grupo de Investigación en Optometría, Universidad de Valencia, Valencia, Spain (PB-M, RM-M); Grupo de Ciencias de la Visión, Universidad de Murcia, Murcia, Spain (PB-M, NL-G); and Université Paris-Sud, Orsay, France (RL).
}

the presence of chromatic ${ }^{2,3}$ and monochromatic aberrations $s^{4-6}$ play a significant role as well. The precise value of DOFi also depends on the specific way DOFi is defined. Whereas some definitions are related to an absolute minimum value of visual acuity (VA), ${ }^{2,7}$ there are others based on relative VA values, for example, dioptric range over which VA exceeds some percentage of its optimum value. ${ }^{8-10}$ In practice, DOFi is usually based on a simple letter legibility criterion. In this case, the letter size plays an essential role in the final DOFi value. ${ }^{11,12}$ As a simple example, most presbyopes recognize the visual loss at near distances when trying to read small text, but not with large font sizes, which are nonetheless out-of-focus by the same amount.

Depth-of-field of the presbyopic eye is a critical determinant of the prescribed add power or the design of contact or intraocular lenses ${ }^{13,14}$ and refractive surgery. ${ }^{15}$ It has been proposed that DOFi is responsible for some or most of the accommodative errors (lead or lag). ${ }^{5}$ Although there are some studies that have examined the origins of accommodative errors, ${ }^{10-12}$ the true origin of the accommodation error remains an unanswered question. Moreover, it has been shown quite recently that the error of accommodation can actually be a "false accommodation error" 
resulting from criterion differences between the subject (for subjective measurements) and the measuring device (for objective ones) when choosing the best image. ${ }^{16,17}$

There have been numerous studies devoted to measuring the DOFi on either side of the far point (FP) of paralyzed lens or presbyopic eyes. ${ }^{1,5,10,18}$ However, there is a lack of data regarding the DOFi as a function of the accommodative state. The reason behind this lack of data is the difficulty to accurately measure the DOFi of the accommodated eye because accommodation cannot be blocked - neither voluntarily nor involuntarily (by means of drugs) to remain at a specific desired accommodation level. The DOFi, although accommodating, can certainly differ from that of the relaxed eye because the pupil size and the aberration pattern change with accommodation. ${ }^{16,19-23}$

Several authors have used an optical system in which the subject focuses his or her attention on a stimulus located at a given distance, while another stimulus close to it can be moved voluntarily by the subject until its image is no longer clear and sharp, that is, until it falls out of their DOFi. ${ }^{2}$ However, it is quite difficult to perform this task with accuracy, because VA decreases very rapidly with stimulus eccentricity. ${ }^{24}$ As far as we are aware, there are only three studies that measured DOFi for objects located between the far and near points. ${ }^{2,25,26}$ Campbell $^{2}$ used a stimulus made up of a vertical row of three dark discs. The vergence was set during the experiment to a fixed -2 diopter (D) value and it was used at a fixation point that presumably led to a steady accommodation state. Two plates, one with a single disc on the left of the vertical row and another one having the disc on the right side, were moved by the subject along an optical bench so as to find the distance range in which both discs could be seen clear simultaneously. In 1998, Mordi and Ciuffreda ${ }^{25}$ used a similar technique to study a large population having a wider age range. For each subject, they measured the subjective DOFi in the middle of the linear part of the stimulus-response curve. Moreover, in 2010, Yao et al. ${ }^{26}$ performed objective and subjective measures of DOFi for $0,-1.5$, and $-4 \mathrm{D}$ stimulus vergence under the hypothesis that the accommodative and perceptual systems have different abilities to detect blur. The system used was similar to that from Campbell, but only measured the distal half of the DOFi. Therefore, estimating the total DOFi with this approach assumes that DOFi is symmetric in the object space. ${ }^{5}$

Although accommodation leads and lags may be influenced by DOFi, there are few studies of DOFi with varying levels of accommodation, and therefore, none of the previous studies answer the key question: why is the actual accommodative response different from the ideal one for most stimulus vergences? In this work, we propose a novel methodology based on wavefront technology to provide an answer for this question.

\section{METHODS}

\section{Subjects}

This study comprises a total of seven eyes - five right and two left ones-from seven trained subjects. The subjects' age ranged from 22 to 44 years, with a mean $( \pm S D)$ value of $29.7( \pm 7.7)$ years. Subjects in this study were staff from the University of Valencia and the University of Murcia. Most subjects had participated in previous accommodation experiments and all of them participated in a short training session to establish a consistent criterion for "objectionable blur." The research followed the tenets of the Declaration of Helsinki and informed consent was obtained from subjects after they heard a detailed explanation of the study.

\section{Apparatus}

A crx1 adaptive optics visual simulator (Imagine Eyes, France) was used to measure, correct, and induce optical aberrations. The simulator has a 1024-lenslet Hartmann-Shack wavefront sensor, a deformable electromagnetic mirror with 52 independent magnetic actuators as compensating element, and a Badal system. A schematic diagram of the setup is shown in Fig. 1.

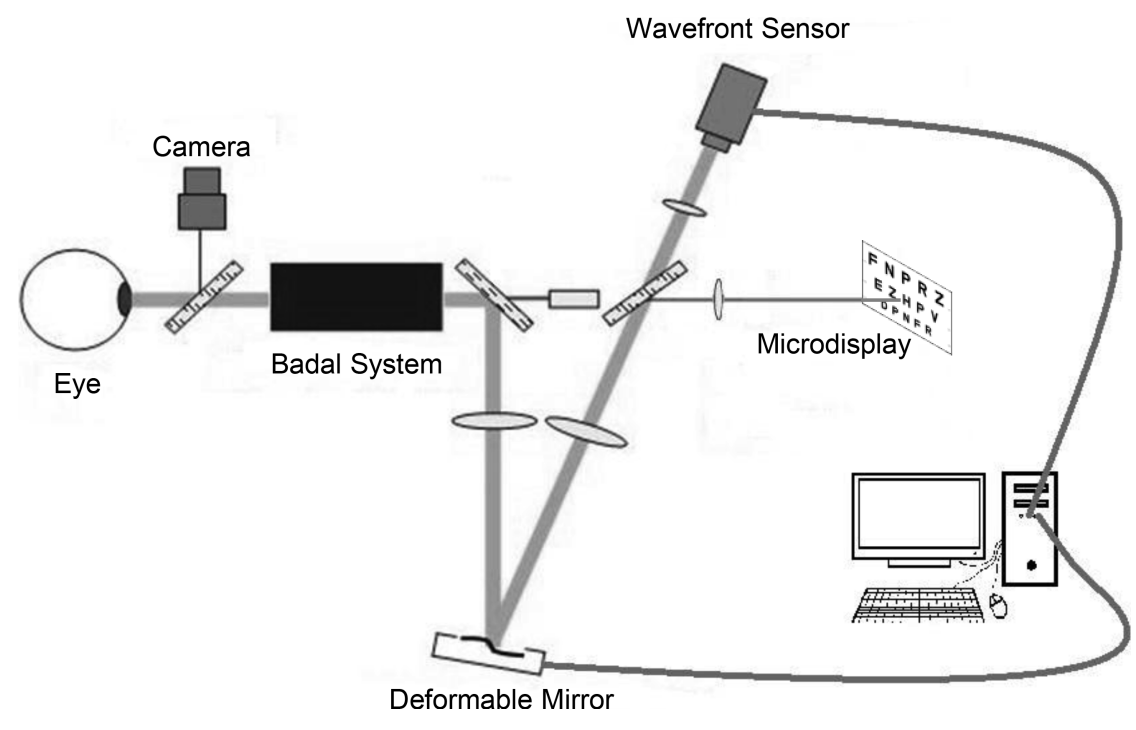

FIGURE 1.

Schematic experimental system. It includes a Badal system to change the vergence of the stimulus, a Shack-Hartmann wavefront sensor to measure the refractive state of the eye, a deformable mirror, and a microdisplay showing the stimulus. 
Wavefront measurements were performed using an $850-\mathrm{nm}$ wavelength near-infrared source. Triggered by the system's software, the deformable mirror can change its shape to correct or induce any aberration pattern expressed in terms of its Zernike decomposition up to sixth order. The target was presented by means of an internal 800 - by 600-pixel microdisplay that has a maximum luminance of $30 \mathrm{~cd} / \mathrm{m}^{2}$ measured from the observer's position. The stimulus (Fig. 1) consisted of three lines of black letters on a white background corresponding to a $\log$ MAR (logarithm of the minimum angle of resolution) of 0.40 (top line), 0.30 (middle line), and 0.22 (lower line). $\mathrm{Z}$ letter in the middle line was used for the fixation during measurements and the fellow eye was occluded.

The position and size of the subject's pupil were monitored by means of a camera. The pupil center, which is automatically located by the software based on a Hartmann-Shack image, was manually aligned to the simulator's optical axis. Good accuracy to measure and generate aberrations for the same wavefront sensor and deformable mirror has been reported elsewhere. ${ }^{9,27,28}$

\section{Experiment}

Data acquisition was carried out in two separate steps. First, a wavefront was measured as a function of the accommodative stimulus by varying the object's vergence from $1 \mathrm{D}$ beyond FP up to $6 \mathrm{D}$ of accommodation in steps of $1 \mathrm{D}$; that is, accommodative demands (ADs) ranging from -1 to $6 \mathrm{D}$ were tested. After each change of stimulus vergence, the subjects were given 1.5 seconds to accommodate before the wavefront was obtained. Subject $\mathrm{N}$ was an exception, who required 3 seconds to feel comfortable. Wavefront measurement required 33 milliseconds. We urged the subjects to try to maintain the stimulus sharp at all times.

Because of their varying ages, some subjects experienced blur beyond $3 \mathrm{D}$ of $\mathrm{AD}$. In these cases, only stimulus vergences where the subject did not experience blur were used. The number of subject analyzed for each $\mathrm{AD}$ was as follows: -1 to $3 \mathrm{D}$ (all subjects), $4 \mathrm{D}$ (six subjects), $5 \mathrm{D}$ (four subjects), and $6 \mathrm{D}$ (two subjects).

For each stimulus vergence, we performed three wavefront measures and computed the average of each Zernike coefficient for the same pupil diameter, $d$. This diameter corresponds to the smallest of the three observed pupils rounded down to the nearest half millimeters. The spherical equivalent refractive error, $M$, for each $\mathrm{AD}$ was then computed in two different ways: one corresponding to the value that minimized the wavefront's variance, RMS, called Zernike refraction and another one corresponding to the paraxial refraction. ${ }^{29}$ The main difference between these two values is that the first one takes into account the effects of high-order aberrations and their change during accommodation whereas the second one is insensitive to highorder aberrations. ${ }^{29,30}$

In the second step of the data-acquisition process, the eye's accommodation was paralyzed by instilling one drop of cyclopentolate $1 \%$, and a single wavefront measurement was then recorded. The Zernike coefficients were then calculated for a pupil corresponding to a diameter $d$ (the minimum diameter each subject had when accommodating at each stimulus demand). Then, for each $\mathrm{AD}$, we modified the deformable mirror to (1) offset the aberrations of the paralyzed eye and (2) add the aberration pattern measured in the first step, thus mimicking the aberrations observed when accommodating to AD. To simulate the natural pupil that the eye had at each $\mathrm{AD}$, an artificial pupil with a diameter $d$ was placed in a plane conjugated with the subject's entrance pupil. Finally, we measured DOFi by placing the stimulus at the vergence for which we induced aberrations in the deformable mirror and then using the Badal system to change the stimulus' vergence in the myopic and hyperopic directions in steps of $0.2 \mathrm{D}$. The subject had to indicate the maximum and minimum vergences for which the stimulus showed an objectionable blur. ${ }^{18}$ The measured vergence range was interpreted to be the DOFi that would have existed in the noncyclopleged eye for that particular $\mathrm{AD}$. The $\mathrm{ADs}$ that were assessed ranged from 0 to $6 \mathrm{D}$, in steps of $1 \mathrm{D}$. Three measures of $\mathrm{DOFi}$ at each $\mathrm{AD}$ were taken. Depth-of-field measurements took less than 15 minutes for every subject; thus, the effect of the cyclopentolate did not change during the experiment.

\section{RESULTS}

Fig. 2 shows each subject's pupil diameter and fourth-order spherical aberration (SA) coefficient, respectively, as a function of the AD.

In Fig. 3, the bars show the DOFi measured for each subject for ADs between 0 and $6 \mathrm{D}$.

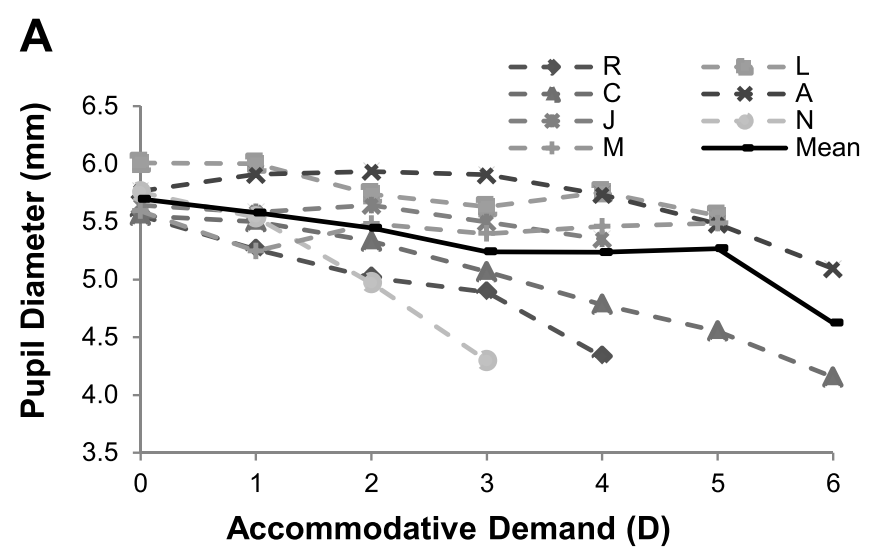

B

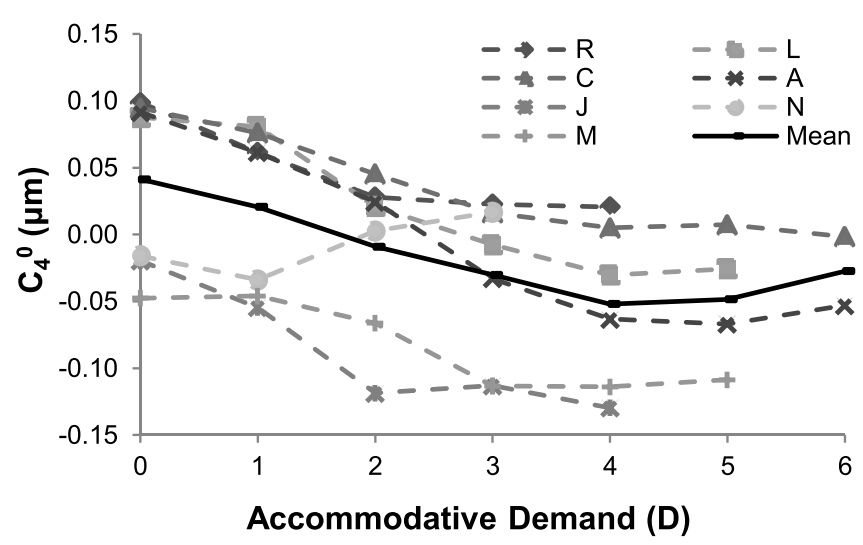

FIGURE 2.

Pupil size (A) and fourth-order SA (B) at different ADs for all subjects and the mean values. 


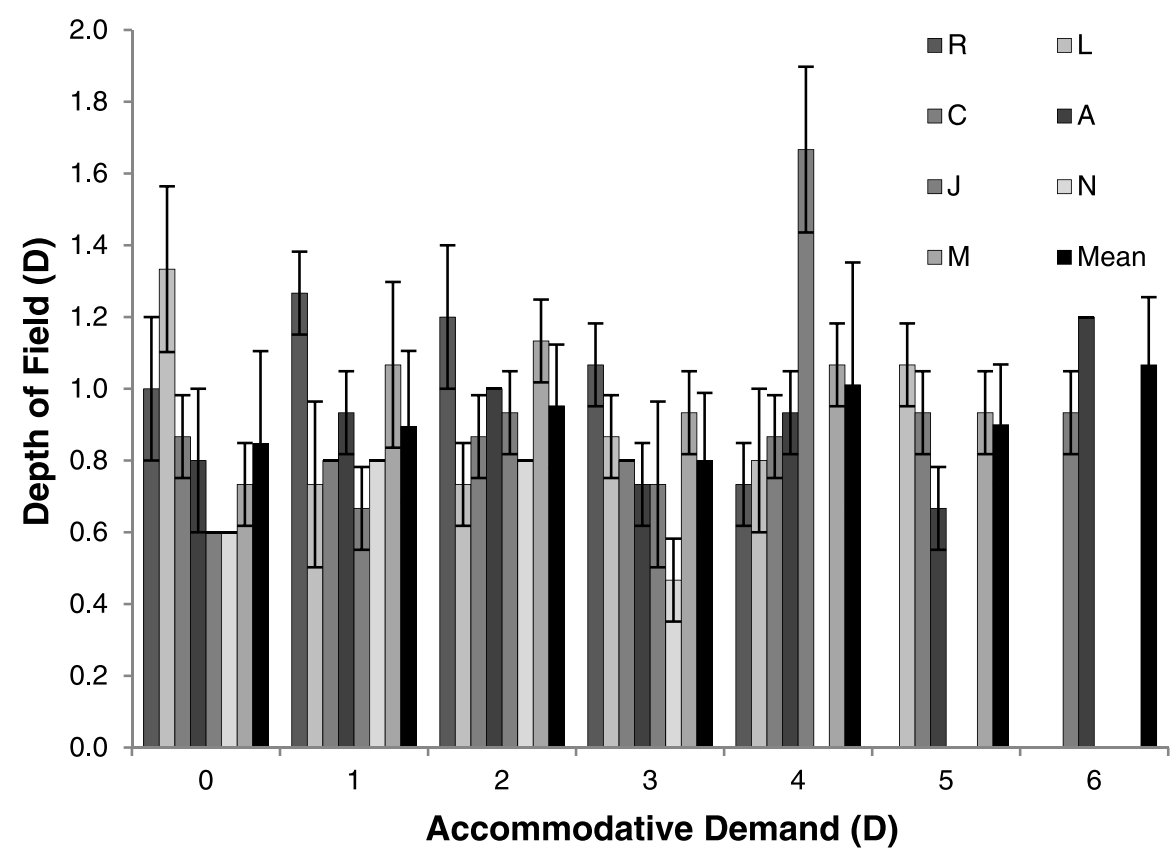

FIGURE 3.

Depth-of-field measured for all subjects at each AD and mean value. Black bars at each AD show the intersubject mean (note that not all subjects were measured at all ADs). Error bars represent \pm 1 SD.

Fig. 4 shows the stimulus-response curve of all subjects. We have plotted the curve until the last $\mathrm{AD}$ for which each subject could see the stimulus clearly.

Finally, Fig. 5 shows the mean paraxial accommodative response obtained in the first step of the methodology. Horizontal bars through each data point show the mean DOFi obtained for each target vergence shown in Fig. 3. When averaging the accommodative response, we have considered at each $\mathrm{AD}$ only the subjects who could see the stimulus clearly.

\section{DISCUSSION}

Fig. 2A shows that the mean $( \pm S D)$ pupil diameter across all subjects was $5.70( \pm 0.16) \mathrm{mm}$ at the paraxial FP, whereas for $6 \mathrm{D}$ of $\mathrm{AD}$, it dropped to $4.62( \pm 0.66) \mathrm{mm}$. It is worth pointing out that for the oldest subjects, $\mathrm{R}$ and $\mathrm{N}$, the pupil size variation curve is steeper (i.e., it has a greater slope). Because these subjects have less accommodative amplitude, this curve profile may be because DOFi is greater for small pupils, ${ }^{2,5,31}$ thus compensating for the

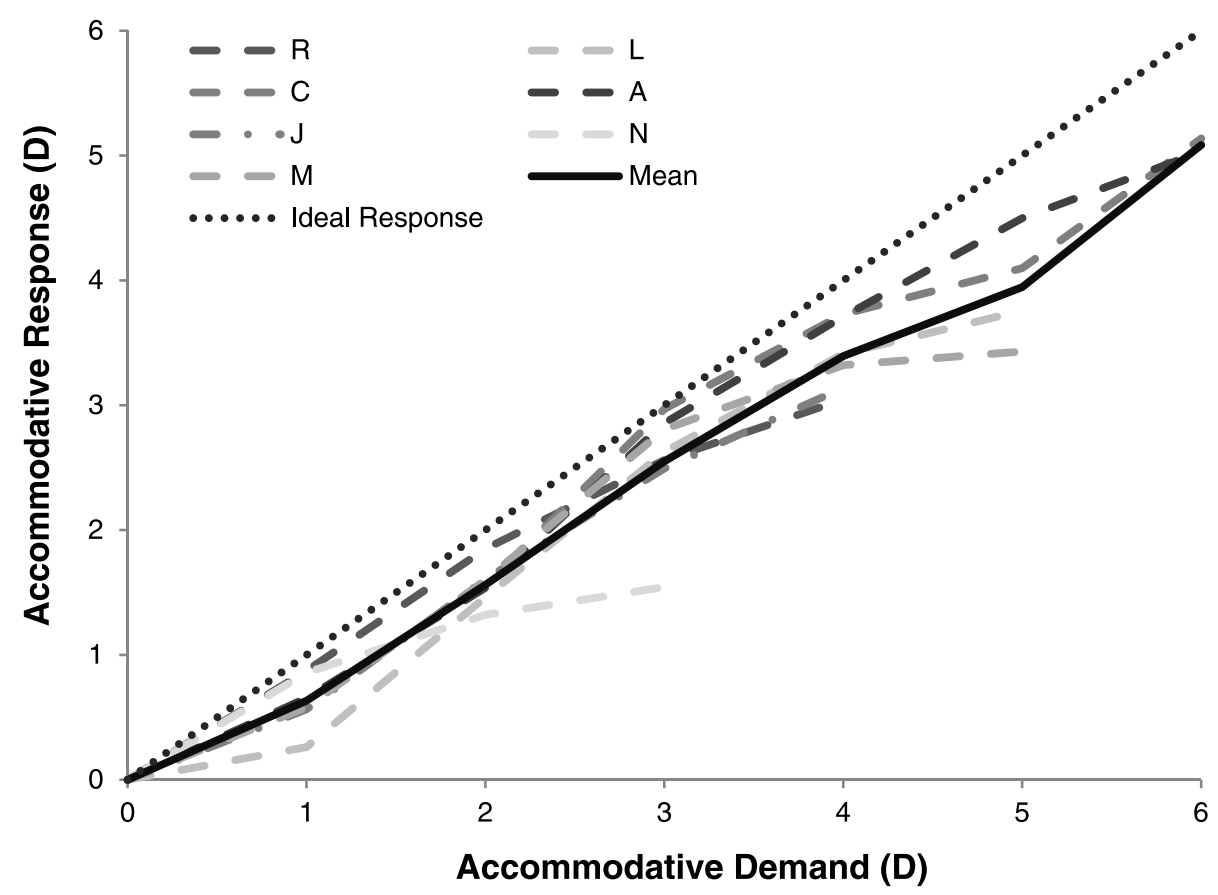

FIGURE 4.

Stimulus-response curve of all subjects. We have plotted the curves until the last AD for which the subject could see the stimulus clear. The black line shows the mean response. 


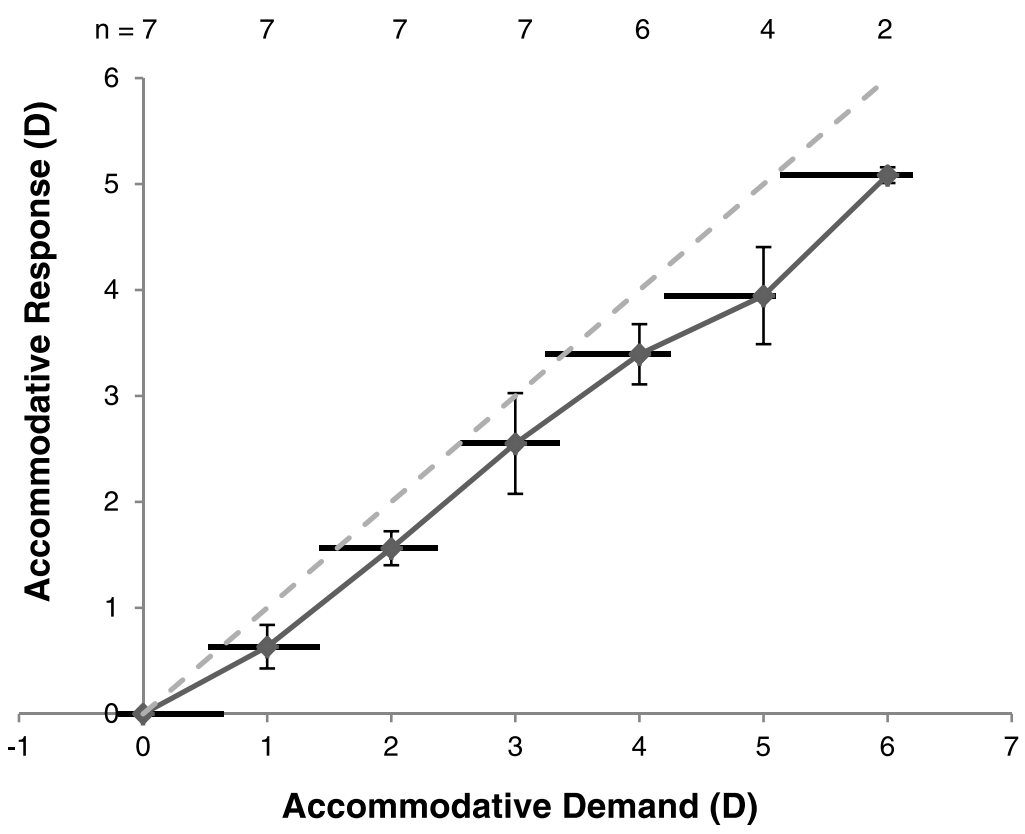

\section{FIGURE 5.}

Solid line: mean paraxial stimulus-response curve. Dotted line: ideal response. Vertical bars represent \pm 1 SD of accommodation. Mean measured DOFi is represented by horizontal bars. $\mathrm{n}$ at the top indicates the number of subjects analyzed at each AD.

lack of accommodation. As shown in Fig. 2B, three of the seven eyes showed negative $\mathrm{SA}$ in the relaxed state. Although this proportion is quite high, it is nonetheless common to find subjects showing negative $S A$ values. ${ }^{30,32,33}$ Nevertheless, on average, we can say that fourth-order SA was positive in the relaxed eye and negative in the accommodated eye as has been observed in other studies. ${ }^{19,21-23}$

Fig. 3 shows that for the stimulus used, the eye's mean DOFi amounts to about 0.9 D. Previous studies have yielded DOFi values that range between 0.8 and $1.2 \mathrm{D}^{2,25,26}$ In particular, Campbell ${ }^{2}$ obtained a DOFi of $0.87 \mathrm{D}$ for $2 \mathrm{D}$ of AD. Mordi and Ciuffreda $^{25}$ reported a DOFi of about $1.28 \mathrm{D}$ for an AD corresponding to the middle point of the linear interval of the accommodative response, whereas Yao et al. ${ }^{26}$ found a DOFi of $1.04 \mathrm{D}$ for $1.5 \mathrm{D}$ of AD.

Assuming that paraxial refraction is able to correctly predict accommodative response, Fig. 5 shows that for all ADs, the visual system shows a certain lag, with the exception of the FP (0 D of $\mathrm{AD}$ ) where the accommodation error has been forced to be zero. ${ }^{17}$ There is a simple reason behind this choice: by definition, the FP represents the minimum vergence of an object that can be clearly seen by a relaxed eye (0 D of accommodative response). Thus, following that definition, there can be no lead at $0 \mathrm{D}$ of $\mathrm{AD}$.
Mean DOFi shown by black bars in Fig. 3 is displayed horizontally in Fig. 5, because it represents a vergence interval in the object space present for each accommodative stimulus. To understand the horizontal position of each bar, we can take a look at Fig. 6, which schematically depicts the scenario for an $\mathrm{AD}$ of $6 \mathrm{D}$. The average accommodation response in this case was $5 \mathrm{D}$, which means that, on average, the subjects presented a 1-D lag. The corresponding DOFi bar indicates that the subjects can clearly see the object within the 6.2- to 5-D dioptric range. This means that when the object is at $6 \mathrm{D}$ of $\mathrm{AD}$, it is nearly at the end of the DOFi that is closest to the eye, which corresponds to about 6.2 D. The other end of the DOFi corresponds to $5 \mathrm{D}$, a plane that is paraxially conjugated with the retinal plane. Conversely, for an $\mathrm{AD}$ of $0 \mathrm{D}$, the $\mathrm{DOFi}$ range goes from -0.2 to $0.65 \mathrm{D}$. In this case, the visual system appears to use the furthermost end of this interval $(-0.2 \mathrm{D})$.

Considering Fig. 5, we can notice that DOFi is asymmetrically distributed with respect to the paraxial refractive state of the eye. That is, the horizontal bar is not symmetrical with respect to the accommodation response curve and the asymmetry depends on the value of the AD. Thus, for a distant object $(\mathrm{AD}=0 \mathrm{D})$, almost all the DOFi lies in the hyperopic sense (objects closer to the eye than the stimulus). However, for an

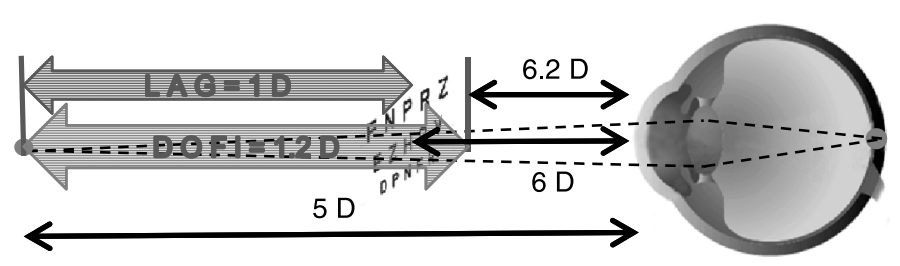

FIGURE 6.

Example of accommodation to a stimulus with $6 \mathrm{D}$ of AD. Accommodative response measured is $5 \mathrm{D}$, lagging $1 \mathrm{D}$. Using its asymmetrical DOFi of $1.2 \mathrm{D}$ $(+1.0$ to -0.2$)$ about the stimulus vergence, the visual system is able to see the stimulus without an apparent blur although the accommodative lag is $1.0 \mathrm{D}$. 
intermediate $\mathrm{AD}$ ( 1 to $3 \mathrm{D}$ ), the DOFi appears to be quite symmetrical about the stimulus distance, whereas for near objects, most of the DOFi expands in the myopic sense (to include objects further away from the eye than the accommodative stimulus). The DOFi's asymmetry change during accommodation can be explained by analyzing the visual effects of the interaction between SA and defocus, ${ }^{34,35}$ as well as the change of SA with accommodation (Fig. 2B).

The relaxed eye usually shows positive SA (Fig. 2B), and Thibos et al. have shown that in the presence of a positive $S A$, a hyperopic plane (negative defocus) with respect to the paraxial image will show a higher-contrast image, but the letters of the object will be more difficult to read owing to the changes in the phase transfer function, producing contrast reversal phenomena. ${ }^{34,35}$ However, a myopic blur (positive defocus) will decrease the contrast of the object without creating phase reversals, allowing a better readability of high-contrast letters. This asymmetry in the effects of defocus may explain why most of the DOFi at $\mathrm{AD}$ equal to $0 \mathrm{D}$ expands to higher values of $\mathrm{AD}$ or negative defocus (Fig. 5). On the contrary, for SA less than 0 (usually in the accommodated eye, Fig. 2B), a similar contrast reversal phenomenon will occur with positive defocus and better legibility with negative defocus. This explains why most of the DOFi for high accommodation values expands toward lower values of $\mathrm{AD}$ (Fig. 5). For SA equal to 0 , around $\mathrm{AD}$ equal to $3 \mathrm{D}$ (Fig. $2 \mathrm{~B}$ ), a symmetry in the DOFi can be expected, as it was indeed obtained (Fig. 5).

Fig. 5 also shows that for practically all ADs, DOFi extends from the paraxial refraction to the ideal accommodation response ( $1: 1$ dotted line). This indicates that the accommodation used by the eye is just enough to see the object correctly. It is interesting to point out that, avoiding the far and near points and their surroundings, DOFi is not needed because the eye can focus the stimulus perfectly well. For instance, Fig. 5 shows that a stimulus at an $\mathrm{AD}$ of $3 \mathrm{D}$ can be in paraxial focus perfectly well if the eye accommodates the amount that accommodated for a stimulus placed at $\mathrm{AD}$ equal to $3.5 \mathrm{D}$. However, even in that case, the visual system is using most of its DOFi to accommodate the minimum.

Our data support the hypothesis that the difference between the ideal and real accommodation response is mainly attributed to the presence of DOFi. That is, when accommodating to near objects, the visual system takes advantage of the full DOFi to change the refractive state of the eye by about the minimum, even if there is enough potential accommodation to improve the retinal image quality.

\section{ACKNOWLEDGMENTS}

We thank Arthur Bradley and Larry N. Thibos for their comments to the interpretation of the results. This work was funded by Fundación Séneca de la Región de Murcia grant 15312/PI/10 to NL-G and by European grant ERC2012-StG 309416-SACCO to RM-M. This study has been presented as a paper in the annual meeting of the Association for Research in Vision and Ophthalmology held in Seattle in 2013.

Received February 10, 2014; accepted July 7, 2014.

\section{REFERENCES}

1. Charman WN, Whitefoot H. Pupil diameter and the depth of field of the human eye as measured by laser speckle. Optica Acta 1977; 24:1211-6.
2. Campbell FW. The depth of field of the human eye. Optica Acta 1957;4:157-64.

3. Legge GE, Mullen KT, Woo GC, Campbell FW. Tolerance to visual defocus. J Opt Soc Am (A) 1987;4:851-63.

4. Ninomiya S, Fujikado T, Kuroda T, Maeda N, Tano Y, Oshika T, Hirohara Y, Mihashi T. Changes of ocular aberration with accommodation. Am J Ophthalmol 2002;134:924-6.

5. Wang B, Ciuffreda KJ. Depth-of-focus of the human eye: theory and clinical implications. Surv Ophthalmol 2006;51:75-85.

6. Rocha KM, Vabre L, Chateau N, Krueger RR. Expanding depth of focus by modifying higher-order aberrations induced by an adaptive optics visual simulator. J Cataract Refract Surg 2009;35:1885-92.

7. Charman WN. Optics of the eye. In: Bass M, ed. Handbook of Optics: Fundamentals, Techniques and Design, vol. 1, 2nd ed. New York, NY: McGraw Hill; 1995:3-54.

8. Yi F, Iskander DR, Collins MJ. Estimation of the depth of focus from wavefront measurements. J Vis 2010;10:3.1-9.

9. Yi F, Iskander DR, Collins M. Depth of focus and visual acuity with primary and secondary spherical aberration. Vision Res 2011;51: 1648-58.

10. Tucker J, Charman WN. The depth-of-focus of the human eye for Snellen letters. Am J Optom Physiol Opt 1975;52:3-21.

11. Lopez-Gil N, Martin J, Liu T, Bradley A, Diaz-Munoz D, Thibos LN. Retinal image quality during accommodation. Ophthalmic Physiol Opt 2013;33:497-507.

12. Heath GG. The influence of visual acuity on accommodative responses of the eye. Am J Optom Arch Am Acad Optom 1956; 33:513-24.

13. Holladay JT, Van Dijk H, Lang A, Portney V, Willis TR, Sun R, Oksman HC. Optical performance of multifocal intraocular lenses. J Cataract Refract Surg 1990;16:413-22.

14. Leyland M, Zinicola E. Multifocal versus monofocal intraocular lenses in cataract surgery: a systematic review. Ophthalmology 2003; 110:1789-98.

15. Dai GM. Optical surface optimization for the correction of presbyopia. Appl Opt 2006;45:4184-95.

16. Lopez-Gil N, Fernandez-Sanchez V. The change of spherical aberration during accommodation and its effect on the accommodation response. J Vis 2010;10:12.

17. Thibos LN, Bradley A, Lopez-Gil N. Modelling the impact of spherical aberration on accommodation. Ophthalmic Physiol Opt 2013;33:482-96.

18. Atchison DA, Charman WN, Woods RL. Subjective depth-of-focus of the eye. Optom Vis Sci 1997;74:511-20.

19. Young T. The Bakerian Lecture: on the mechanism of the eye. Phil Trans R Soc Lond 1801;91:23-88.

20. Cheng H, Barnett JK, Vilupuru AS, Marsack JD, Kasthurirangan S, Applegate RA, Roorda A. A population study on changes in wave aberrations with accommodation. J Vis 2004;4:272-80.

21. Tscherning M. Physiologic Optics, Dioptrics of the Eye, Functions of the Retina, Ocular Movements and Binocular Vision. English translation, 3rd ed. Philadelphia, PA: The Keystone Press; 1920.

22. Ivanoff A. On the influence of accommodation on spherical aberration in the human eye, an attempt to interpret night myopia. J Opt Soc Am 1947;37:730.

23. Atchison DA, Collins MJ, Wildsoet CF, Christensen J, Waterworth MD. Measurement of monochromatic ocular aberrations of human eyes as a function of accommodation by the Howland aberroscope technique. Vision Res 1995;35:313-23.

24. Rabbetts RB. Bennett and Rabbetts' Clinical Visual Optics, 4th ed. Baltimore, MD: Butterworth-Heinemann; 2007. 
25. Mordi JA, Ciuffreda KJ. Static aspects of accommodation: age and presbyopia. Vision Res 1998;38:1643-53.

26. Yao P, Lin H, Huang J, Chu R, Jiang BC. Objective depth-of-focus is different from subjective depth-of-focus and correlated with accommodative microfluctuations. Vision Res 2010;50:1266-73.

27. Sabesan R, Ahmad K, Yoon G. Correcting highly aberrated eyes using large-stroke adaptive optics. J Refract Surg 2007;23:947-52.

28. Fernández EJ, Vabre L, Hermann B, Unterhuber A, Povazay B, Drexler W. Adaptive optics with a magnetic deformable mirror: applications in the human eye. Optics Express 2006;14:8900-17.

29. Thibos LN, Hong X, Bradley A, Applegate RA. Accuracy and precision of objective refraction from wavefront aberrations. J Vis 2004;4:329-51.

30. López-Gil N, Fernández-Sánchez V, Thibos LN, Montés-Micó R. Objective amplitude of accommodation computed from optical quality metrics applied to wavefront outcomes. J Optom 2009; 2:223-34.

31. Marcos S, Moreno E, Navarro R. The depth-of-field of the human eye from objective and subjective measurements. Vision Res 1999; 39:2039-49.
32. Castejon-Mochon JF, Lopez-Gil N, Benito A, Artal P. Ocular wavefront aberration statistics in a normal young population. Vision Res 2002;42:1611-7.

33. Thibos LN, Hong X, Bradley A, Cheng X. Statistical variation of aberration structure and image quality in a normal population of healthy eyes. J Opt Soc Am (A) 2002;19:2329-48.

34. Cheng X, Bradley A, Ravikumar S, Thibos LN. Visual impact of Zernike and Seidel forms of monochromatic aberrations. Optom Vis Sci 2010;87:300-12.

35. Thibos LN, Bradley A, Liu T, Lopez-Gil N. Spherical aberration and the sign of defocus. Optom Vis Sci 2013;90:1284-91.

Norberto López-Gil Facultad de Óptica y Optometría Universidad de Murcia Campus de Espinardo 30100 Murcia Spain e-mail:norberto@um.es 